\title{
Tough and Strong: Cross-Lamella Design Imparts Multifunctionality to Biomimetic Nacre
}

Hemant Kumar Raut, ${ }^{1,2}$ Alan F. Schwartzman, ${ }^{1}$ Rupambika Das, ${ }^{2}$ Fan Liu, ${ }^{3}$ Lifeng Wang, ${ }^{3}$ Caroline A. Ross, ${ }^{1 *}$ Javier G. Fernandez*2

${ }^{1}$ Department of Materials Science and Engineering, Massachusetts Institute of Technology, Cambridge, Massachusetts 02139, United State

${ }^{2}$ Division of Engineering Product Development, Singapore University of Technology and Design, 8 Somapah Rd, Singapore 487372, Republic of Singapore

${ }^{3}$ Department of Mechanical Engineering, Stony Brook University, Stony Brook, NY 11794, USA

\section{SUPPLEMENTARY FIGURES AND \\ INFORMATION}

* Corresponding authors’ email addresses: caross@ @it.edu, javier.fernandez@sutd.edu.sg 


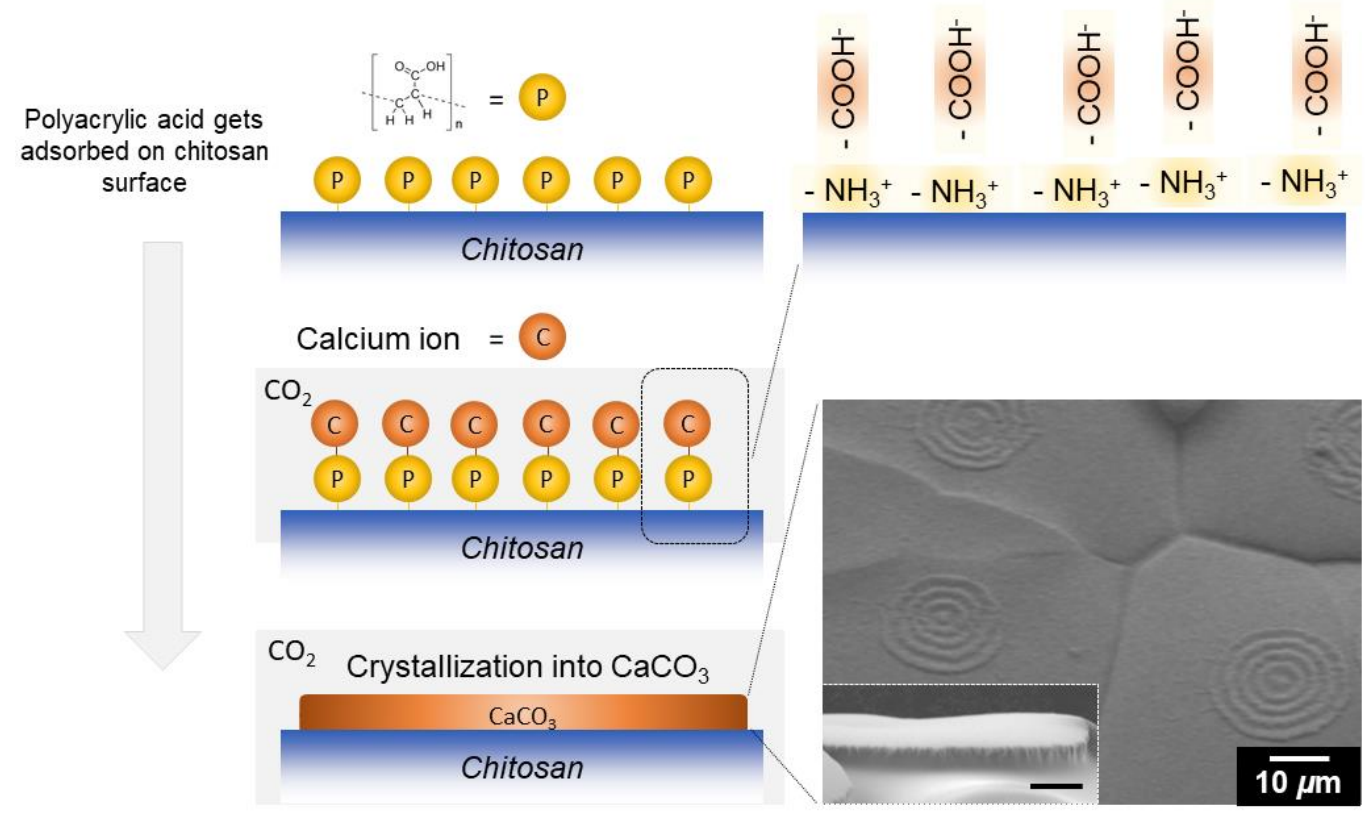

Figure S1: Schematic of the biomineralization by $\mathrm{PAA}-$ based $\mathrm{CaCO}_{3}$ precursor. Chitosan being a cationic biopolymer with hydroxyl group $(-\mathrm{OH})$ and primary amine groups $\left(-\mathrm{NH}_{2}\right)$, becomes protonated $\left(\mathrm{NH}_{3}{ }^{+}\right)$in acidic conditions. During the biomineralization, the $-\mathrm{COOH}$ groups of PAA are adsorbed on the chitosan substrate and act as a template for epitaxial nucleation of $\mathrm{Ca}^{2+}$. The PAA- $\mathrm{Ca}^{2+}$ complex is subsequently adsorbed layer-upon-layer and eventually undergoes an amorphous to crystalline transformation, resulting in the formation of $\mathrm{CaCO}_{3}$ film as shown in the inset. 

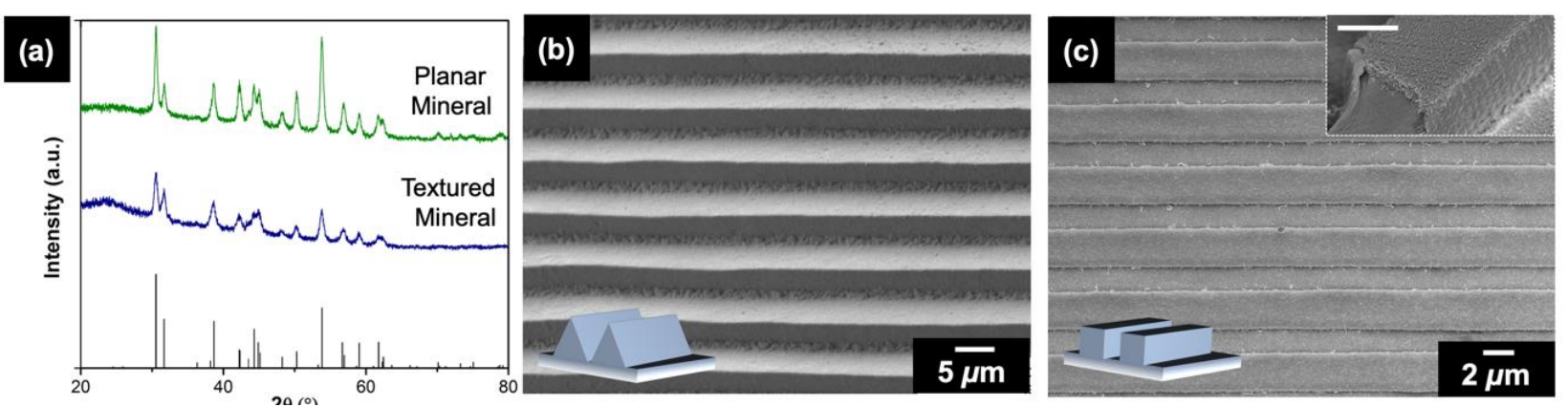

Figure S2: (a) The XRD of the patterned and planar $\mathrm{CaCO}_{3}$ films synthesized by the PAAinduced biomineralization. They match the reference pattern for the aragonite polymorph of $\mathrm{CaCO}_{3}$ crystals. (b) Patterned aragonite with a saw-tooth profile. (c) Patterned aragonite with a square profile. The inset shows that the aragonite minerals follow the underlying patterned geometry. 


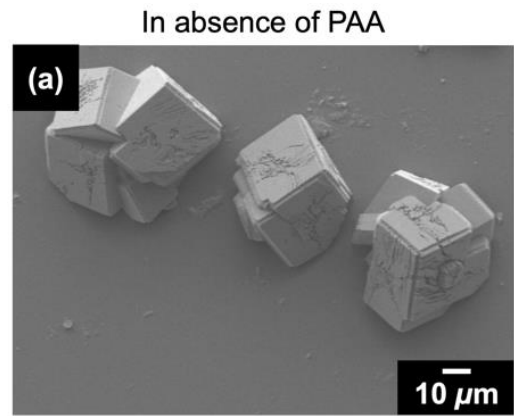

In presence of PAA

\section{(b)}

$1 \bar{\mu} \mathrm{m}$
$6 \mathrm{~h}$ mineralization

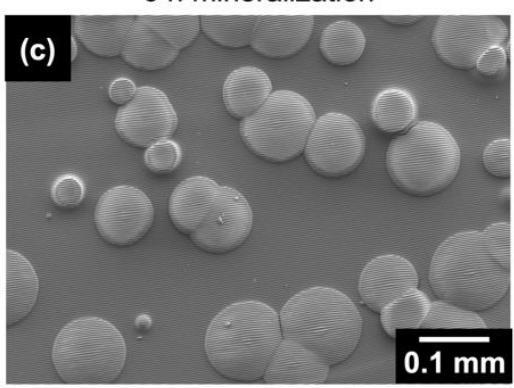

High conc. of PAA

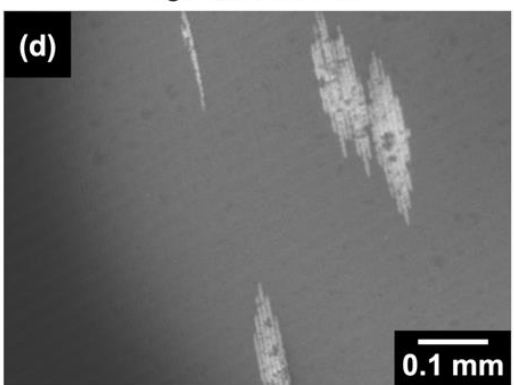

$\sim 18 \mathrm{~h}$, No pre-submerging in PAA

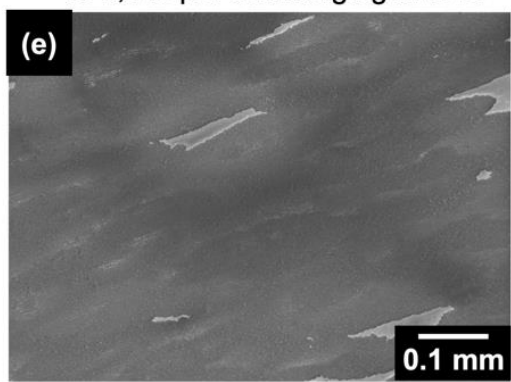

$\sim 18 \mathrm{~h}$, Pre-submerging in PAA

Figure S3: Influence of various factors on the biomineralization of aragonite. (a) Rhombohedral crystals formed in the absence of PAA [poly(acrylic acid)] in the mineralization precursor (5 $\mathrm{mM} \mathrm{CaCl}_{2}$ in water). (b) PAA-containing precursor $(\sim 10 \mu \mathrm{g} / \mathrm{ml} \mathrm{PAA})$ induces synthesis of patterned $\mathrm{CaCO}_{3}$ mineral films on a patterned chitosan surface. (c) A higher concentration of PAA $(\sim 30 \mu \mathrm{g} / \mathrm{ml})$ suppresses crystallization resulting the formation of nonuniform isolated islands of aragonite mineral. (d) With the $10 \mu \mathrm{g} / \mathrm{ml}$ PAA-based mineralization precursor, the yield (area covered) by aragonite films as mineralization span increases $(\sim 6 \mathrm{~h})$. (e) A longer duration of mineralization $(\sim 18 \mathrm{~h})$ further improves the coverage of aragonite films. (f) Pre-submersion of the chitosan films in the mineralization precursor for 2-3 h before commencement of mineralization results in dramatic improvement in the yield of aragonite film growth. 
1 wt. \% Chitosan
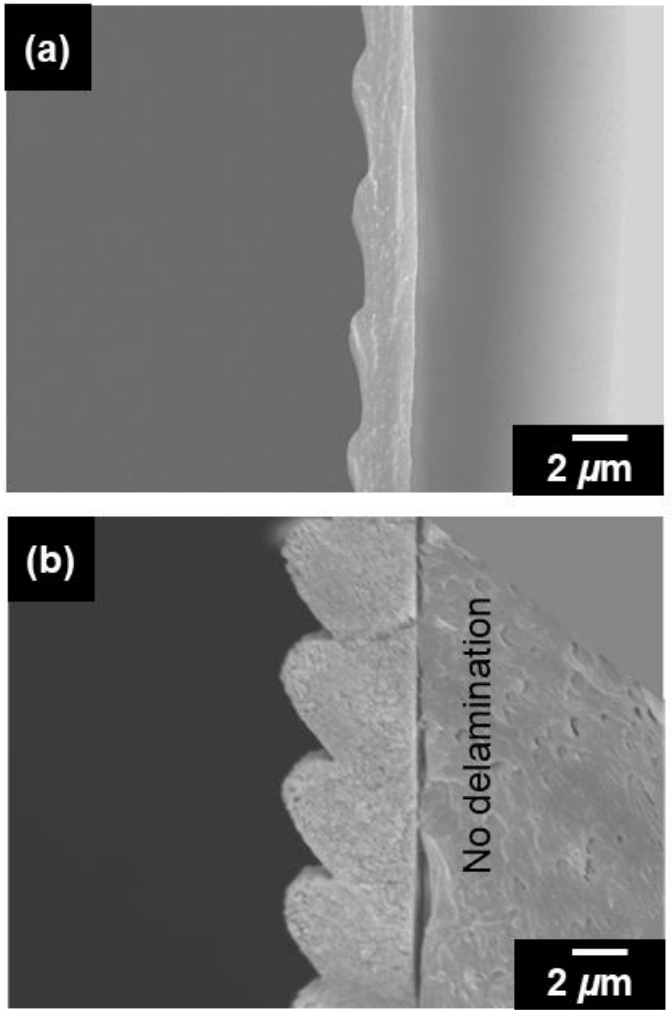

2 wt. \% Chitosan
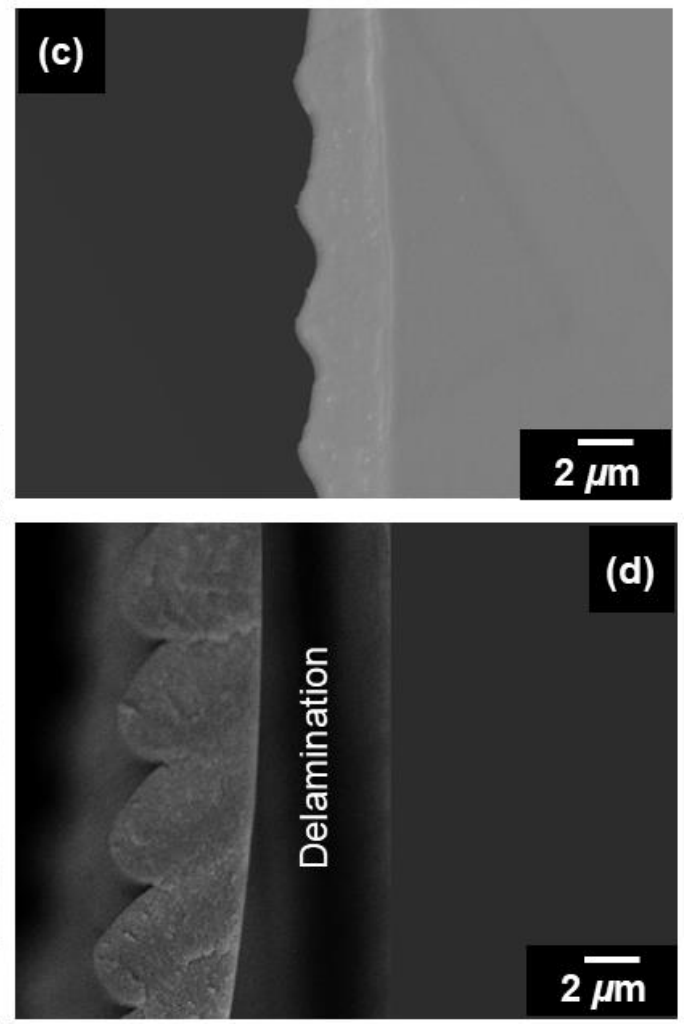

Figure S4: Exfoliation of the patterned CA (chitosan-aragonite) films. Patterned chitosan films produced using different weight percent of chitosan, namely, (a) $1 \mathrm{wt} . \%$ and (c) $2 \mathrm{wt} . \%$, results in different thickness of residual layer in the patterned films. (b) The mineralized CA film (made using $1 \mathrm{wt} \% \%$ chitosan) could not be fully delaminated from the backing PMMA sheet. (d) In contrast, mineralized CA film (made using $2 \mathrm{wt} . \%$ chitosan) could be delaminated fully without causing damage to the film. 


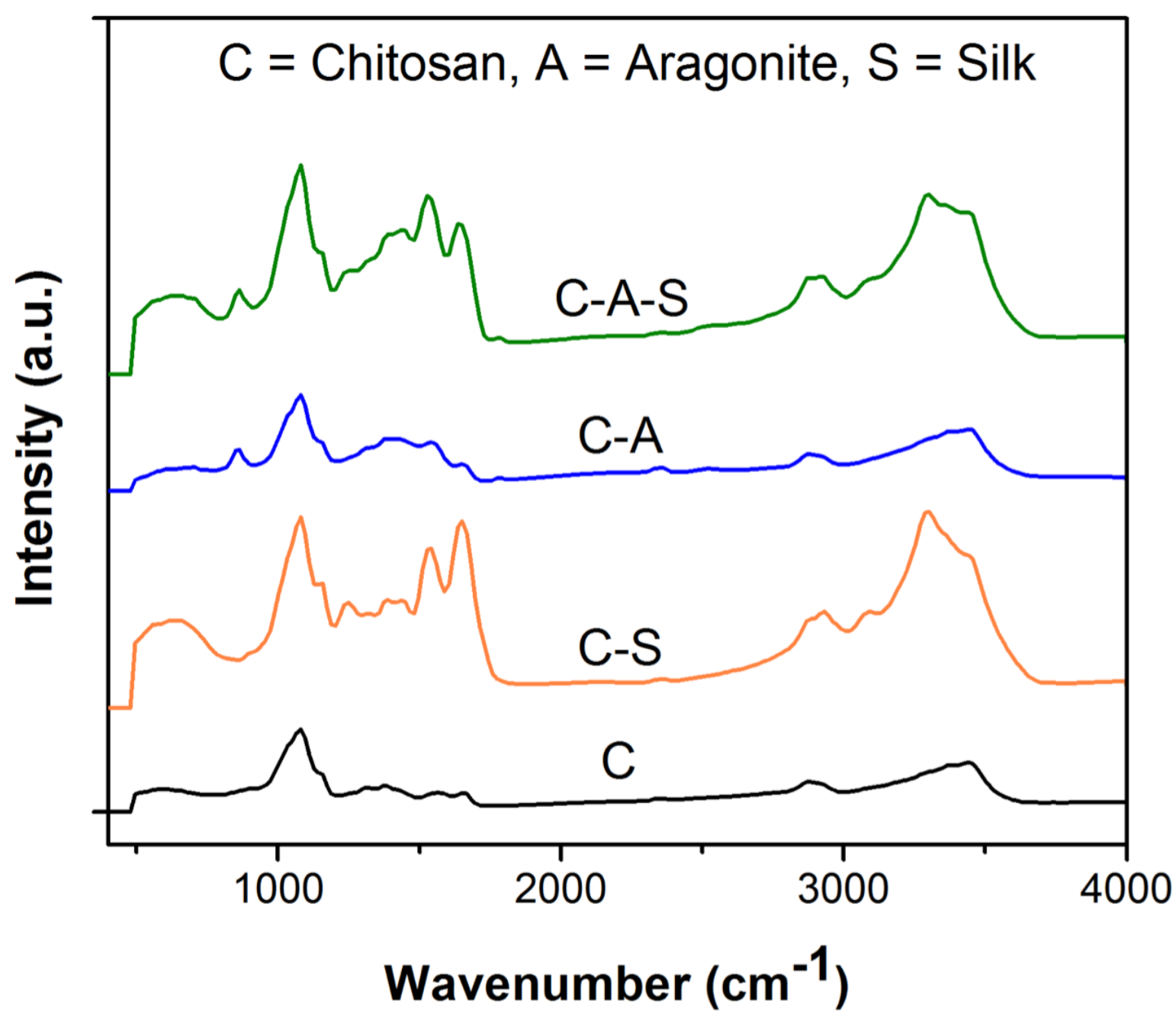

Figure S5: The FT-IR spectra of the constituents of the composite, that is ChitosanAragonite-Silk (C-A-S). The spectra of chitosan films, CA bilayer, and chitosan films coated with silk (CS bilayers) are also shown for comparison. The spectra of all four types of films exhibit the characteristic peaks of chitosan, namely, the stretching vibrations of the amide group (amide I), O-H group and C-H group at $1658 \mathrm{~cm}^{-1}, 3478.68 \mathrm{~cm}^{-1}$, and $2924.13 \mathrm{~cm}^{-1}$ respectively and the bending vibrations of the $\mathrm{N}-\mathrm{H}$ (amide II band), $\mathrm{C}-\mathrm{H}$ and $\mathrm{O}-\mathrm{H}$ at 1571.05 $\mathrm{cm}^{-1}, 1422.53 \mathrm{~cm}^{-1}$ and $1378.16 \mathrm{~cm}^{-1}$, respectively. ${ }^{1}$ On the other hand, the films with silk coating (CS films and CAS films) show additional absorption bands at $1655 \mathrm{~cm}^{-1}$ (amide I) and $1559 \mathrm{~cm}^{-1}$ (amide II) which are assigned predominantly to random coil conformations. ${ }^{1,2}$ Upon methanol treatment, the amide I and II bands of these films shift to lower wavenumbers, 1623 $\mathrm{cm}^{-1}$ and $1530 \mathrm{~cm}^{-1}$, respectively. This indicates that the conformation after methanol-treatment of the SF film is predominantly the $\beta$-sheet form. ${ }^{3}$ In contrast, the films incorporated with aragonite showed distinctive additional peaks at $875 \mathrm{~cm}^{-1}$ and $745 \mathrm{~cm}^{-1}$ which match the characteristic bands of $\mathrm{CaCO}_{3}$. 

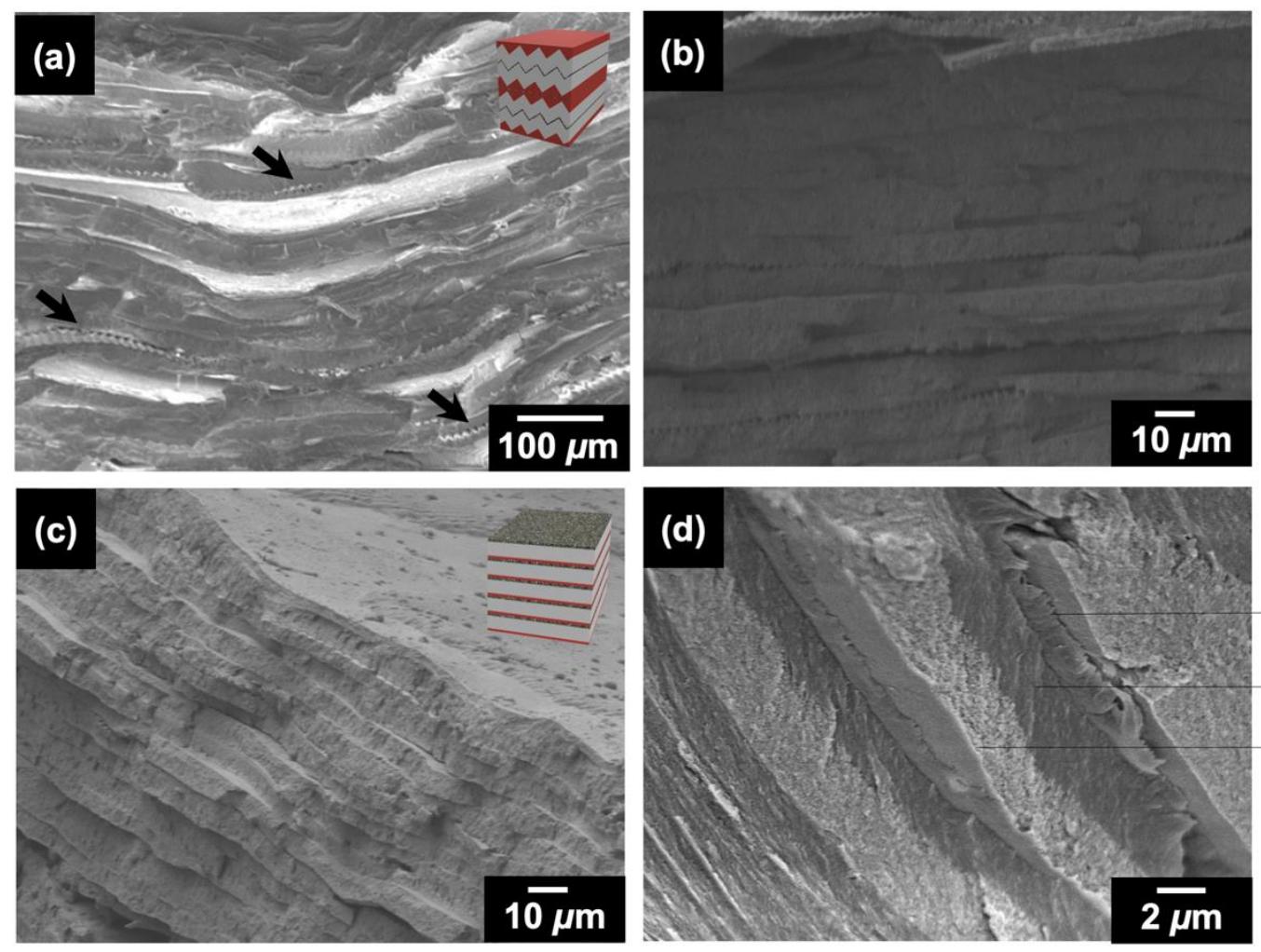

Silk fibroin

Aragonite

Chitosan

Figure S6: Cross-sectional (CS) SEM images of the composite. Interlocked-mineral composite's (a) low magnification CS view (b) high magnification CS view. Planar-mineral composite's (c) low magnification CS view (d) high magnification CS view. The latter shows the planar CA films bonded together by the silk fibroin layer in-between. 


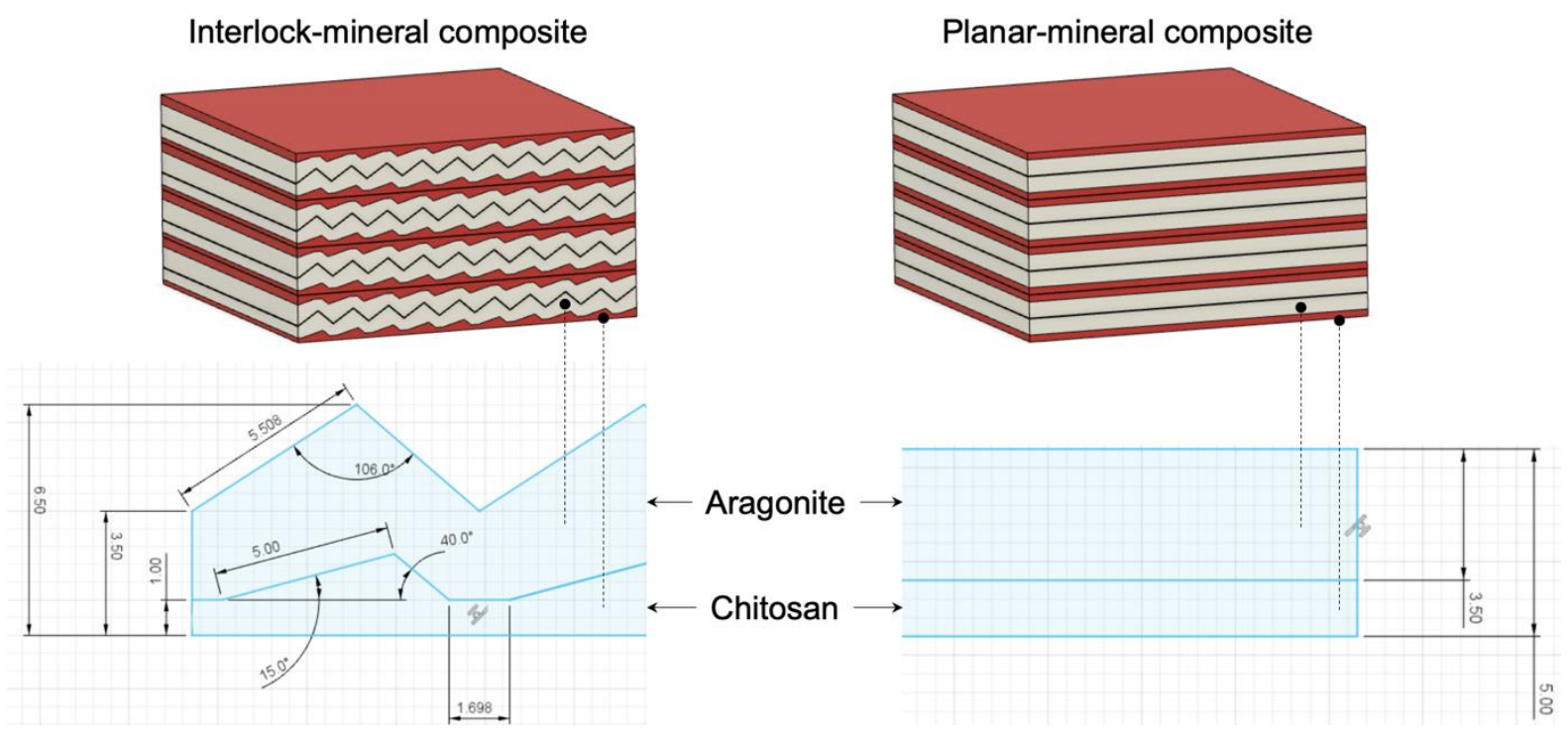

Figure S7: Calculation of volume fraction. Approximate dimension (based on SEM analysis) of typical platelets present in a (left) interlocked-mineral composite and (right) planar mineral composite. The volume fraction in both cases is calculated to be $\sim 70 \%$ based on the method in ref. ${ }^{4}$. 


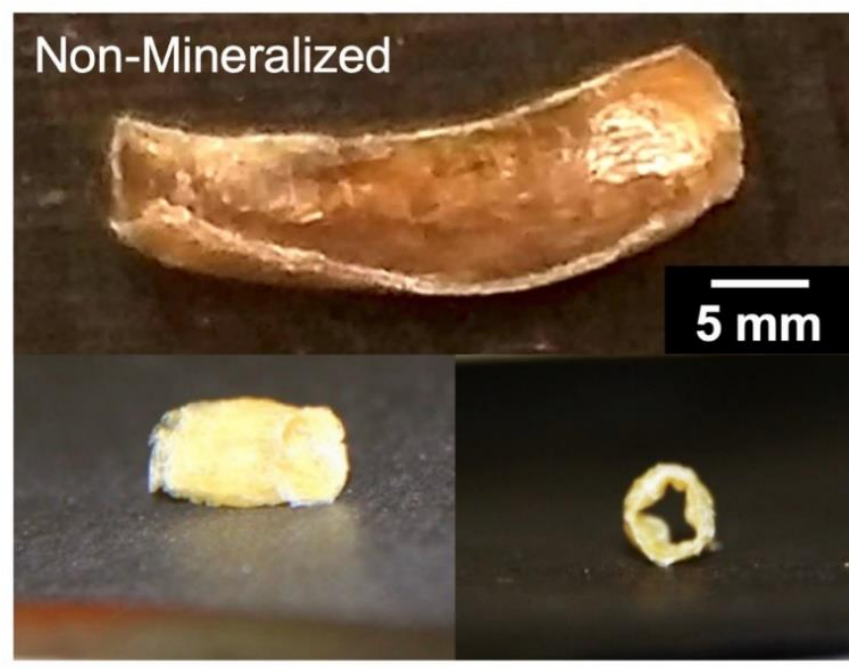

Figure S8: Non-Mineralized Chitosan-Silk Composite. The non-mineralized specimen comprises alternating layers of chitosan and silk. After drying, the composite shrinks and deforms. The shell made using the chitosan-silk layers does not form a perfect tubular structure due to drying-induced shrinkage. 
(a)
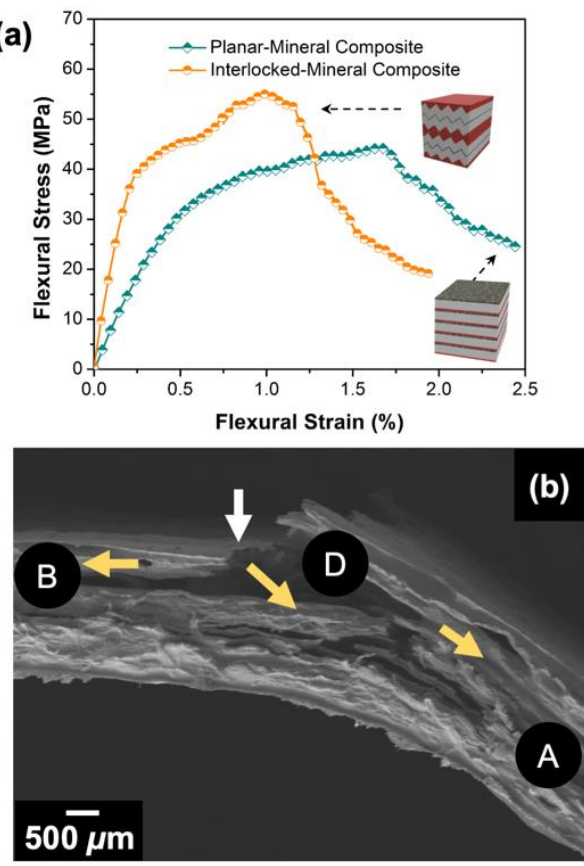

(c)

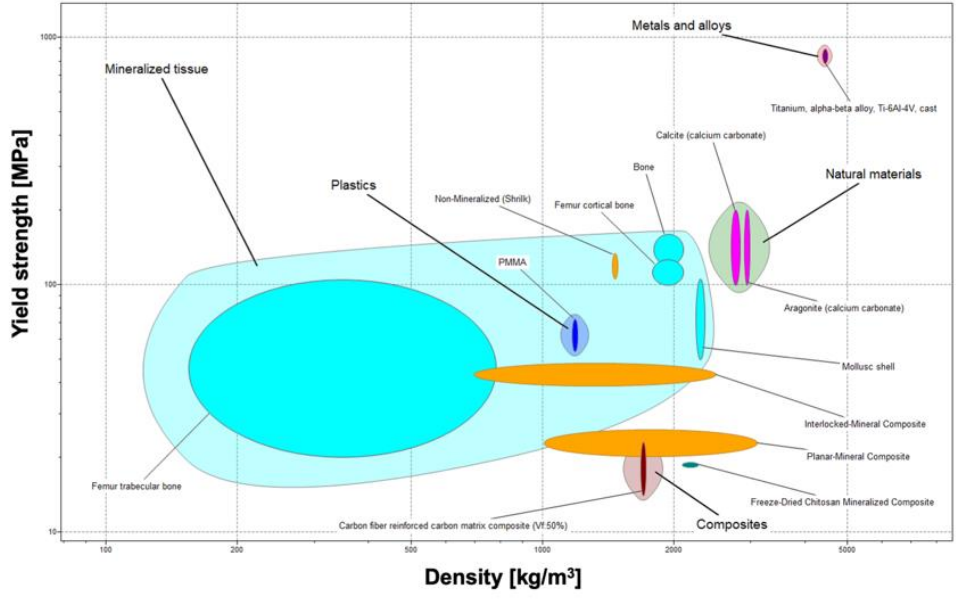

Figure S9: Flexural Characterization of the Interlocked-Mineral Composite and Comparison with Natural Materials and Nacre-Like Composites. (a) Flexural stress vs. strain of the interlocked-mineral composites and the planar-mineral composite. (b) A graceful fracture behaviour is seen when the interlocked-mineral composite is subjected to a three-point bending experiment. The original crack branched into sub-cracks (indicated by "B") and deflected (at "D"), eventually getting arrested (at "A"). Localized delamination around the regions " $\mathrm{A}$ " and " $\mathrm{B}$ " indicate the activation of extrinsic toughening mechanisms within the composite that prevents catastrophic failure. (c) Ultimate tensile strength $(E)$ plotted against specific density $(\rho)$ for interlocked-mineral and planar-mineral composites juxtaposed against mineralized biological materials (bone and mollusc shell), common implantable materials (such as $\mathrm{Ti}$ alloys), plastics and fibre reinforced composites. The interlocked-mineral composite shows a higher specific tensile strength than that of the planar-mineral composite (specific density is nearly the same for both specimen). 
a

Day1
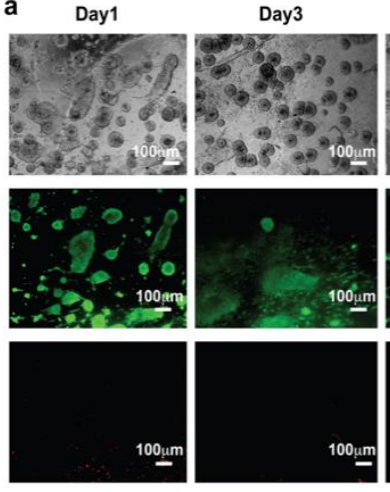

2. 3.100 um
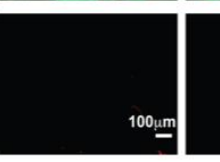

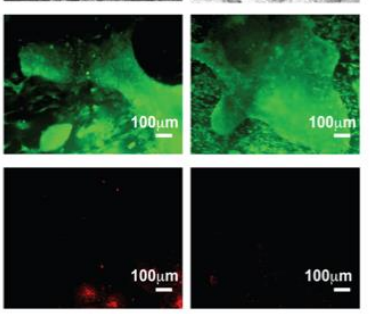

Day5

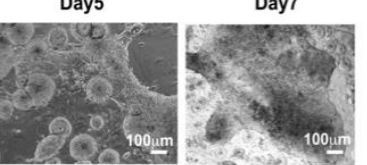

b
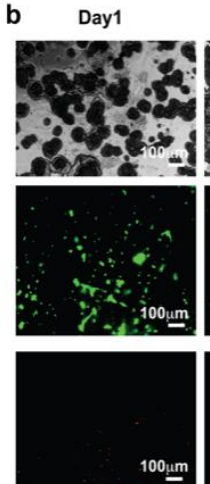

$100 \mu \mathrm{m}$

E14 cells on patterned surface

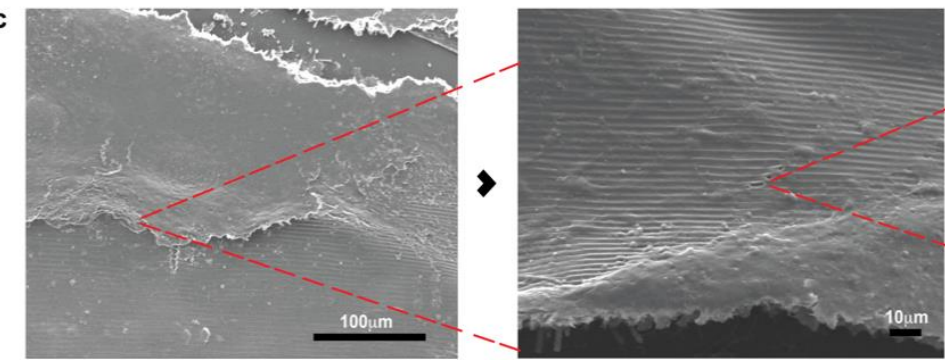

Non-Patterned Surface

Day3

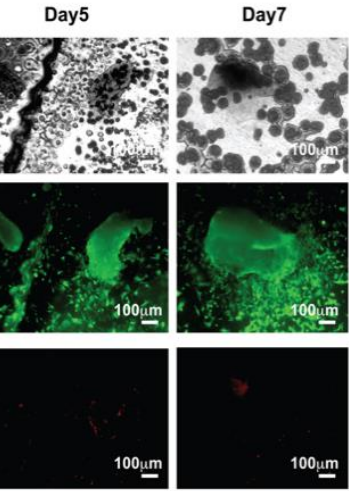

$100 \mu$

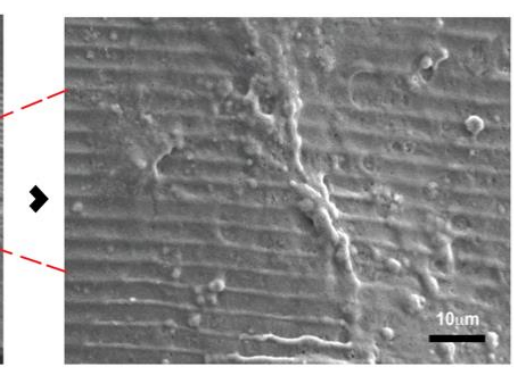

Figure S10: Cell viability assay performed on the composites. (a) E14TG2A cells seeded on textured-mineral composite specimens and studied for bio-compatibility for 7 days. Calcein AM stains the live cells whereas Ethidium Homodimer-2 stains the dead cells (Scale-100 $\mu \mathrm{m}$ ). (b) Surface of the planar-mineral composite studied for cell viability over a period of 7 days

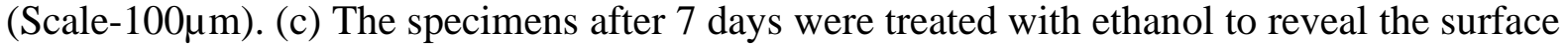
morphology by SEM (Scale-100 $\mu \mathrm{m}, 10 \mu \mathrm{m}, 10 \mu \mathrm{m})$. 
Table S1: Summary of mechanical properties.

\begin{tabular}{|c|c|c|c|c|c|c|}
\hline & $\begin{array}{l}\text { UTS } \\
\text { (MPa) }\end{array}$ & $\begin{array}{l}\text { TT } \\
(\mathrm{kJ} / \mathrm{m3})\end{array}$ & $\operatorname{Er}(\mathbf{G P a})$ & FS (MPa) & $\begin{array}{l}\text { WoF } \\
(\mathrm{kJ} / \mathrm{m3})\end{array}$ & $\begin{array}{l}\bar{\rho} \quad(\times 1000 \\
\left.\mathrm{kg} / \mathbf{m}^{3}\right)\end{array}$ \\
\hline $\begin{array}{l}\text { Interlocked- } \\
\text { mineral } \\
\text { composite }\end{array}$ & $\begin{array}{l}43.59 \pm \\
4.5\end{array}$ & 284.71 & $20.4 \pm 5.4$ & $\begin{array}{l}55.211 \quad \pm \\
5.6\end{array}$ & 733.51 & $\begin{array}{l}1.54 \\
0.74\end{array}$ \\
\hline $\begin{array}{l}\text { Planar- } \\
\text { mineral } \\
\text { composite }\end{array}$ & $\begin{array}{ll}23.01 \quad \pm \\
2.8\end{array}$ & 72.68 & $16 \pm 4.3$ & $\begin{array}{ll}41.728 \quad \pm \\
4.8\end{array}$ & 538.45 & $\begin{array}{l}1.512 \\
0.74\end{array}$ \\
\hline
\end{tabular}

UTS $=$ Ultimate tensile strength

$\mathrm{TT}=$ Tensile toughness

$\mathrm{Er}=$ Elastic modulus

FS = Flexural strength

$\mathrm{WoF}=$ Work of fracture

$\overline{\boldsymbol{\rho}}=$ Specific density 


\section{Reference:}

1. Fernandez, J. G.; Ingber, D. E., Unexpected Strength and Toughness in ChitosanFibroin Laminates Inspired by Insect Cuticle. Adv. Mater. 2012, 24, 480-484.

2. $\quad$ Park, S. J.; Lee, K. Y.; Ha, W. S.; Park, S. Y., Structural Changes and Their Effect on Mechanical Properties of Silk Fibroin/Chitosan Blends. J. Appl. Polym. Sci. 1999, 74, 25712575.

3. Kweon, H.; Ha, H. C.; Um, I. C.; Park, Y. H., Physical Properties of Silk Fibroin/Chitosan Blend Films. J. Appl. Polym. Sci. 2001, 80, 928-934.

4. Mao, L.-B.; Gao, H.-L.; Yao, H.-B.; Liu, L.; Cölfen, H.; Liu, G.; Chen, S.-M.; Li, S.K.; Yan, Y.-X.; Liu, Y.-Y.; Yu, S.-H., Synthetic Nacre by Predesigned Matrix-Directed Mineralization. Science 2016, 354, 107-110. 